\title{
Precordial-Intracardiac Phonocardiographic Correlative Study of Ventricular Septal Defect*
}

\author{
Tsuguya Sakamoto, M.D., Zen'ichiro Uozumi, M.D., Nobuyoshi \\ Kawai, M.D., Sheng Yu Chang, M.D., and Hideo Ueda, M.D.
}

\section{SumMary}

Precordial and intracardiac phonocardiographic correlation was investigated in 28 cases with ventricular septal defect (VSD) to confirm the diagnostic value of intracardiac phonocardiography and to clarify the clinical as well as physiological significance of the point of maximum intensity (PMI) of the regurgitant systolic murmur of VSD. At the same time, the teleological use of catheterization was documented and the recent concept of the auscultatory area was modified.

(1) The regurgitant systolic murmur of VSD was localized within the right ventricle (RV) or partially transmitted toward the pulmonary artery (PA) and had the PMI somewhere in the RV. The murmur was pansystolic in timing and had a wide frequency span. A few exceptional cases were described, but the murmur of these cases became typical following the administration of methoxamine. The findings due to the associated anomalies were documented. The fact that the presence of regurgitant systolic murmur within the $\mathrm{RV}$ is the most sensitive diagnostic clue of VSD was confirmed.

(2) The PMI of the regurgitant systolic murmur within the RV was so localized that it was easy to locate the site of the septal defect in almost all cases.

(3) The localized PMI within the RV was the best site for the sampling of any measurements. The oxygen content was significantly high at this point when compared to those of randam sampling. This fact enables us to utilize teleologically the cathcterization to detect the shunt. Methoxamine administration made the oxygenation of the sample conclusive in doubtful cases.

(4) In a dorsoventral projection to the chest wall, intracardiac PMI of the regurgitant systolic murmur coincided with the precordial PMI in all cases. Therefore, the sampling at the site immediately beneath the precordial PMI was also recommended instead of the intracardiac PMI whenever the intracardiac phonocardiography was not available. Moreover, the site of septal defect could be anticipated in many cases with a reasonable accuracy based on this topographical correspondence of both PMIs.

From the Second Department of Internal Medicine, Faculty of Medicine, University of Tokyo, Tokyo, 113 .

* Selected part of the presentation read before the 32nd Annual Meeting of the Japanese Circulation Society in March, 1968.

Received for publication January 18, 1969. 
(5) The correspondence of the 2 (intracardiac and precordial) PMIs suggests that there is a direct transmission of the murmur from the origin to the chest wall. In this regard, the present authors made a minor modification to the " revised auscultatory areas" for the sake of the regurgitant systolic murmur of VSD and reserved a name of "interventricular septal area " to the precordial PMI.

\section{Additional Indexing Words :}

Cardiac auscultation Point of maximum intensity (PMI) of murmur Auscultatory area Methoxamine Cardiac catheterization

7 HE definite value of intracardiac phonocardiography (I-PCG) rests on its ability to localize the origin of heart sounds and murmurs. This is the reason why the cardiac catheterization routinely utilizes I-PCG as an integral part of the diagnostic studies. ${ }^{1-14)}$ Particularly, the identification of the specific murmur within the right ventricle has been regarded as a final diagnostic proof of ventricular septal defect (VSD), even when the catheterization data are equivocal. ${ }^{11-19}$

The purpose of the present study is, beside the re-appraisal of the diagnostic value of I-PCG in VSD, to investigate the physiological meaning of the point of maximum intensity (PMI) of the systolic murmur of VSD by means of the correlative study of precordial and intracardiac acoustic phenomena. Thereby, the teleological use of cardiac catheterization with or without I-PCG is documented to make the diagnosis of VSD reliable.

\section{Materials and Methods}

Twenty-eight cases of VSD were the material of the present study. Sex distribution was 17 male and 11 female, and the age ranged from 12 to 34 with an average of 21. A half of cases was uncomplicated VSD with a left-to-right shunt less than $50 \%$. Two other cases were also uncomplicated but had two communications between ventricles. Pulmonary hypertension (PH) was present in 2 cases, one of which had hyperkinetic $\mathrm{PH}$ and the other had Eisenmenger reaction. Five cases had aortic insufficiency (AI), 3 had pulmonic stenosis (PS), 1 had mitral insufficiency (MI), and 1 was complicated by patent ductus arteriosus (PDA). In general, the cases of uncomplicated VSD had no apparent cardiac symptoms and signs except the characteristic murmur. The complicated cases also had a typical pansystolic murmur except the cases with $\mathrm{PH}$.

All cases had routine physical and laboratory examinations. Phonocardiography was done in all as previously described. ${ }^{20)}$ Amyl nitrite test ${ }^{21)}$ and methoxamine test ${ }^{22)}$ were performed in all. Right heart catheterization was done, under the fluoroscopy using image-intensifier, inserting the catheter via saphenous vein, and pressures were recorded by means of Statham pressure transducer (P23Db). Oxygen content was determined by Van Slyke's method and cardiac output and left-to-right 
shunt were determined by the Fick principle. Cine-angiocardiography was done in 7 cases which had some diagnostic problems. Surgery was performed primarily in the complicated cases. Thus, the final diagnosis concerning the site of left-to-right shunt was established in nearly all cases. Exceptions were the uncomplicated cases with the shunt less than $30 \%$ or the cases which had no reasonable bases for the calculation (4 cases), in which the site of shunt was finally decided by the repeated sampling and the localized PMI of the regurgitant systolic murmur within the right ventricle.

I-PCG was done using double lumen phonocatheter. * The element of barium titanate of $10 \mathrm{~mm}$. in length was mounted at the tip of the catheter and the side-hole for the pressure and sampling was located just proximal to the element $(14 \mathrm{~mm}$. from the top of the catheter).

Special procedures: Prior to catheterization, the PMI of VSD murmur in the recumbent position, which was previously checked by routine phonocardiography, was re-confirmed by auscultation using a small bell of the Leatham stethoscope, ${ }^{24}$ ) and a small metal plate was attached on it. This point coincided with the site of systolic thrill, whenever it was felt. Pressure measurements and blood samplings were carried out successively from the pulmonary artery (PA), right ventricle (RV : outflow tract, inflow tract and mid-portion), right atrium (RA), and venae cavae. I-PCG was recorded at the same areas. Subsequently, the intracardiac PMI of the regurgitant systolic murmur was looked around throughout the right ventricle. Once it was located, the tip of catheter was checked fluoroscopically, so that the intracardiac PMI was projected to the chest wall in a dorsoventral direction. Such a procedure enables us to correlate topographically the sites of the 2 (intracardiac and precordial) PMIs on the chest wall. Blood sampling was repeatedly done at this site. Whenever it was possible to locate steadily the catheter tip at the intracardiac PMI, amyl nitrite as well as methoxamine tests were performed (13 cases), and the blood sampling was done during the latter test in some cases.

Monitoring and recording: Beside the oscillographic monitoring, acoustical phenomena were also monitored by a speaker system or head-phone, which were quite useful to locate the PMI within the heart. Multi-channel photographic recorder (Sanei Sokki Co.) was used for the simultaneous recording of multi-filter characteristics of PCG and the same amplification of the apparatus was utilized to compare the relative intensity of the murmur from various recording sites. Simultaneously, Sanborn photographic recorder was used for the pressure tracing and 1 of the filter characteristics of PCG. The latter was fed into the $\mathrm{AC}$ input of the ECG amplifier (Model 350-3200) from the output of the multi-filter system phonocardiograph. ${ }^{20)}$ These 2 recorders were operated simultaneously and both had ECG tracing as a reference. In nearly all cases, the simultaneous intracardiac and precordial PCGs were recorded to determine the exact timing of the murmurs. Paper speed was 100 (occasionally 75) mm./sec.

* Fukuda Denki Co., Cournand double lumen catheter of No. 5 to 9 in size (for I-PGG No. 5 to 6, and for I-PCG and sampling No. 8 to 9 was suitable) was manufactured for the I-PGG catheter. The frequency response is, according to the method of measurement proposed by Schloss and Strasberg, ${ }^{22)}$ fiat from 1,000 to $150 \mathrm{~Hz}$ and $6 \mathrm{~dB} /$ oct. slope of decrease below $150 \mathrm{~Hz}$ (in this instance, the input impedance was $1 \mathrm{meg-ohm)}$. 


\section{Results}

\section{Intracardiac Phonocardiographic Signs:}

All but 4 cases had typical pansystolic murmur in the RV (Fig. 1). In 2 cases with supracristal VSD, the regurgitant murmur was decrescendo and not pansystolic, but became typical murmur afer methoxamine administration (Fig. 2). One of the 2 cases with $\mathrm{PH}$ had crescendo-decrescendo systolic murmur in the RV and this became pansystolic following methoxamine administration (Fig. 3). The other case of Eisenmenger reaction had no systolic murmur within the RV.

The murmur of VSD had a wide frequency span and was extremely intense at the site of regurgitant jet (PMI) and the withdrawal of the catheter 1 to

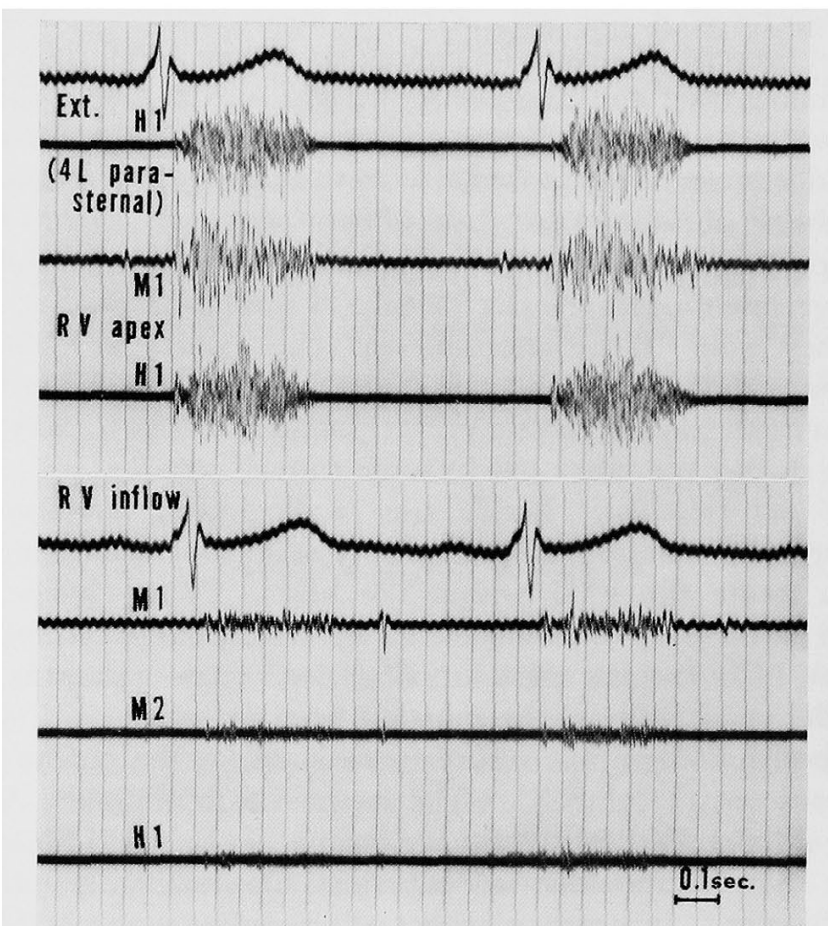

Fig. 1. Patient S. T., 16-year-old male. Apical muscular VSD. A pansystolic murmur of grade V/VI with thrill had its PMI in the 4th left interspace parasternally (above : Ext. 4L parasternal, H1). The corresponding intracardiac PMI was beneath the precordial PMI and it was fairly localized at the right ventricular apex (above : RV apex, $\mathrm{Ml}$ and H1). Transmission of this murmur within the $\mathrm{RV}$ was not marked as it was shown in the tracing from the inflow tract (below: RV inflow, M1, M2 and $\mathrm{H} 1$ ). The oxygenation at the site of intracardiac PMI was distinctly conclusive.

Legends for $P C G: L 2=50 \mathrm{~Hz} / 6 \mathrm{~dB}, \mathrm{M} 1=100 \mathrm{~Hz} / 12 \mathrm{~dB}, \mathrm{M} 2=200 \mathrm{~Hz} / 24$ $\mathrm{dB}, \mathrm{H} 1=400 \mathrm{~Hz} / 24 \mathrm{~dB}$ and $\mathrm{H} 2=600 \mathrm{~Hz} / 24 \mathrm{~dB}$. 


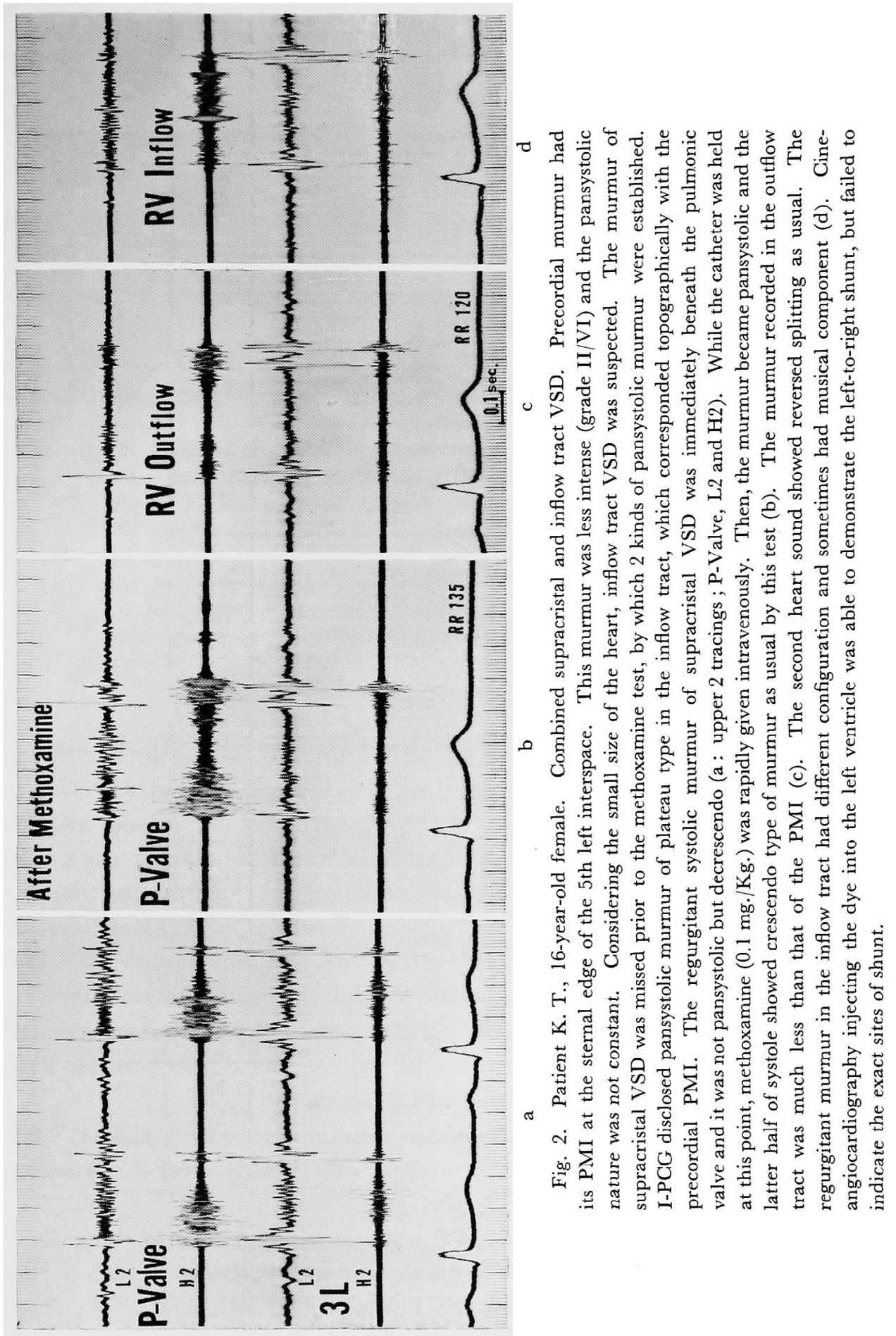




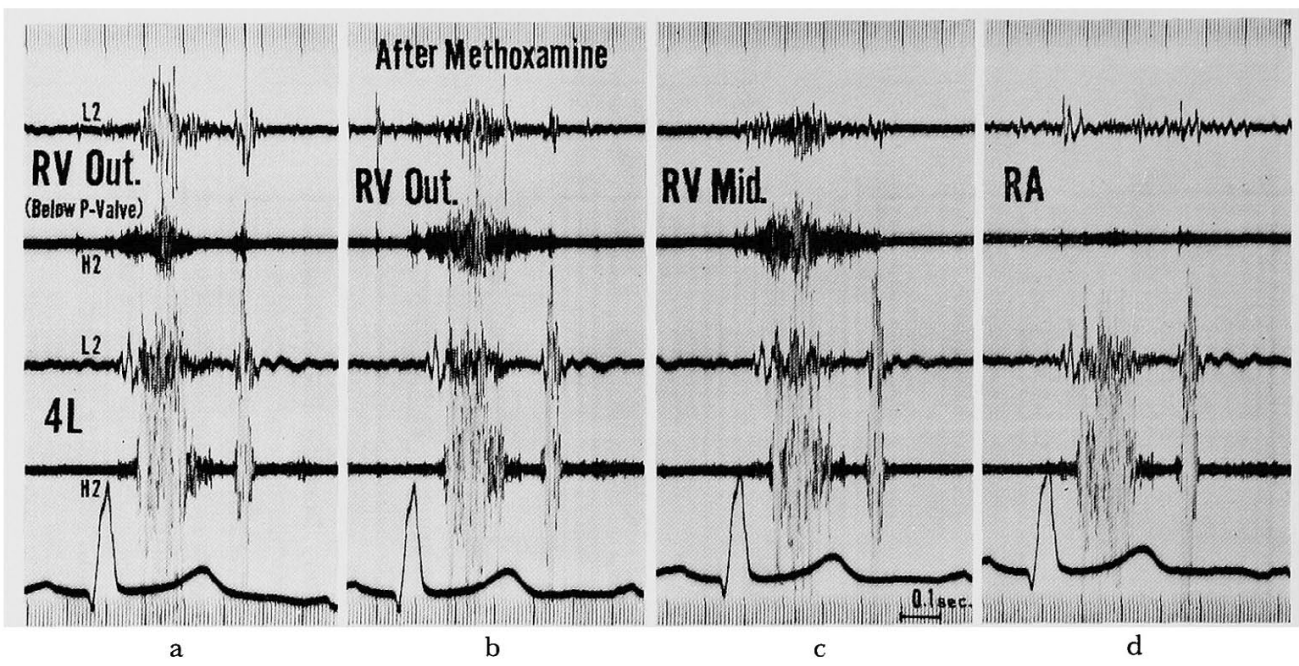

Fig. 3. Patient S. Y., 33-year-old male. VSD with hyperkinetic PH. Aortic systolic pressure was higher than pulmonic one (cf. Table I), and cineangiocardiography revealed a relatively large outflow tract VSD. The precordial systolic murmur was not pansystolic but it was ejection type. The second heart sound was intense. After administration of methoxamine, a pansystolic murmur of crescendo-decrescendo configuration appeared from the outflow tract to the mid-portion of RV (b and $c$ : in these figures, the effect of methoxamine had almost disappeared). The frontal projection of the intracardiac PMI to the precordium was in $4 \mathrm{~L}$. Graham Stcell murmur was present in $2 \mathrm{~L}$ and beneath the pulmonic valve (not shown in this figure).

$2 \mathrm{~cm}$. from the PMI usually caused the significant decrease in the intensity of the murmur. Thus the intracardiac PMI was located without difficulty in each case. Transmission of the murmur to the RA was exceptional and the intensity was extremely low. The same was true in the coronary sinus (2 cases were tested) and this was definite differential diagnostic clue from the murmur of mitral insufficiency. On the other hand, the murmur of VSD was recorded at the pulmonic valve area, particularly in the cases of outflow tract VSD. This was thought to be due to the impact of regurgitant jet to the catheter (i.e. vibration of the catheter), because the pullback tracing from PA demonstrated the accelerated increase of the murmur until the catheter reached to the PMI and then the murmur was attenuated rather suddenly.

In the PA, there was definite ejection systolic murmur ("relative" PS) which was more intense than that of normal cases. However, this murmur was low-pitched and the amplitude was much less than that of VSD. In contrast, the murmur of "organic" PS was louder than that of "relative" PS, and was quite different in the frequency span. This was proved by the pullback tracing with the same amplification of each frequency band; "organic" PS gave larger amplitude particularly in the high-frequency band, 
L
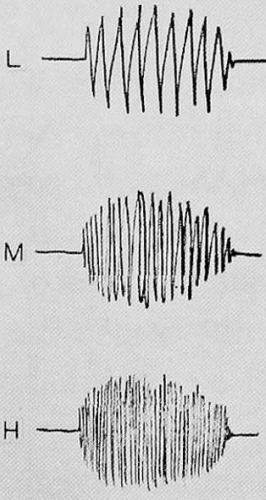
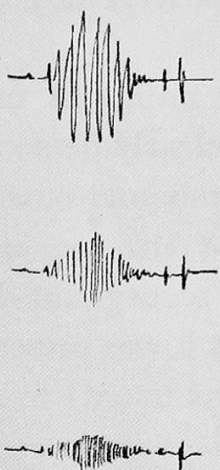
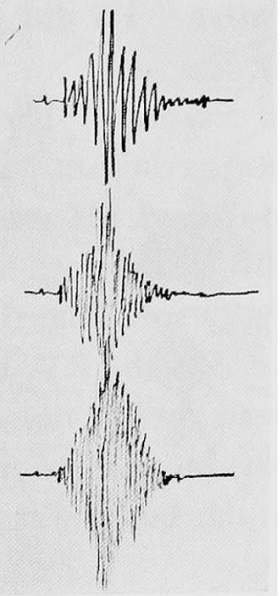

$\underset{\text { Organic }}{\text { OS }}$

VSD

Relative

PS

Fig. 4. Schematic presentation of the frequency-intensity relationship of the murmurs of VSD, relative PS (so-called flow murmur) and combined organic PS. Details: see text.

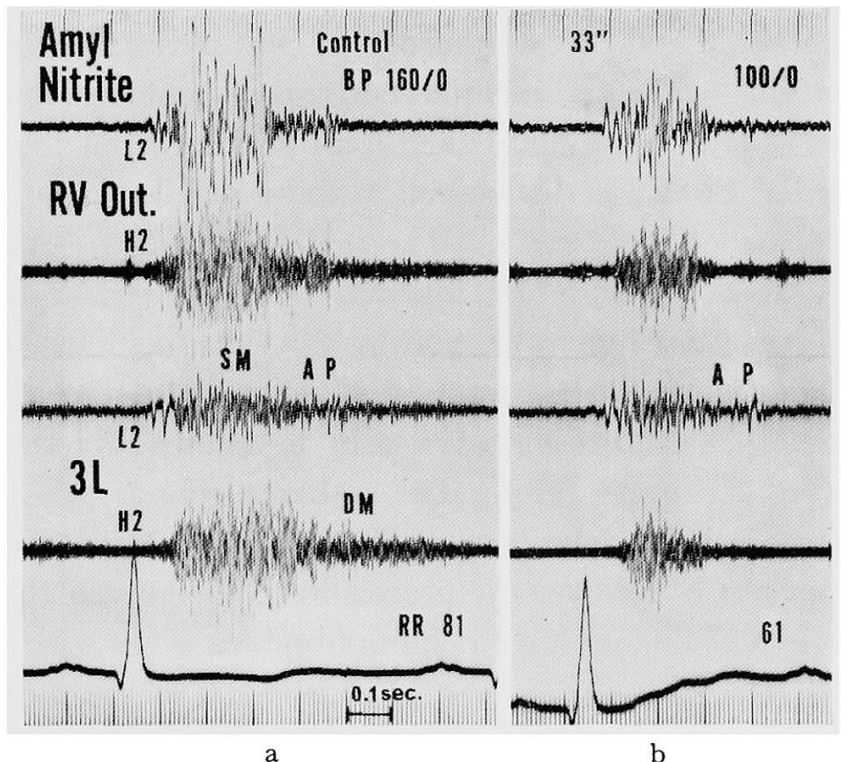

Fig. 5. Patient M. N., 24-year-old male, Outflow tract VSD complicated by AI. The PMI of the precordial murmur of VSD was in $3 \mathrm{~L}$, and the PMI of regurgitant diastolic murmur of AI was in the same area (a: lower 2 tracings). The intracardiac PMI was beneath the precordial PMI of the murmur of VSD, and there was also a faint diastolic murmur of AI (a : upper 2 tracings). Amyl nitrite inhalation caused the attenuation of the murmur of VSD, and the murmur of AI disappeared ( $b: a$ and $b$ are the parts of the semi-continuous tracing with the same amplification of the apparatus). Cineangiocardiography confirmed the diagnosis. Reproduced from the previous publication. . $^{\text {I }}$ 
whereas "relative" PS did relatively large amplitude in the low-frequency band (Fig. 4).

Left-sided murmurs: The continuous murmur of PDA which was not typical on the precordium was clearly demonstrated in the PA. The systolic murmur of co-existed MI was maximal outside of the right ventricular area fluoroscopically determined and this remained after surgical correction of VSD. Generally speaking, the regurgitant diastolic murmur of co-existed AI was not recorded in the $\mathrm{RV}$, but it was present in one case in the outflow tract and disappeared (or greatly attenuated) by amyl nitrite inhalation (Fig. 5). In one case, the murmur of AI was recorded when the catheter was pushed to the atrial septum, but it was not recorded within the RA even in the vicinity of the septum.

\section{Intracardiac and Precordial Correlation of PMI:}

Principally, the 2 PMIs (intracardiac and precordial) were corresponded topographically to each other. Namely, the catheter tip positioned at the intracardiac PMI was exactly coincided with the metal plate on the precordium (precordial PMI) when the fluoroscopy was performed in a dorsoventral direction. According to the site of interventricular communication judged by the intracardiac PMI, cine-angiocardiographic and surgical data, the corresponding precordial PMI was distributed as follows (Fig. 6):

1) Supracristal VSD (2 cases): The septal defect is present immediately beneath the pulmonic valve. The murmur was localized at the site where the catheter tip was placed as to be held by the valve leaflets. In both cases, the murmur was atypical and became typical following methoxamine administration (vide ante). The precordial PMI was in the second left interspace (sternal margin) (2L) (Fig. 6: upper left). The catheter tip was beneath this point. In one case with co-existing infundibular PS, the murmur of VSD was superimposed on the murmur of PS over the precordium. However, the I-PCG gave 2 kinds of systolic murmur within the infundibulum.

2) Outflow tract VSD (16 cases): The defect is in the outflow tract below the crista supraventricularis. Pars membranacea is usually involved. Generally, the murmur well transmitted toward PA, but the PMI was located definitely below the pulmonic valve. The transmission of the murmur toward inflow tract area was not conspicuous (Fig. 7). The precordial PMI corresponding to these intracardiac PMIs was distributed from 2L to 5L (Fig. 6: upper right), but the majority (9 out of 15 cases) was in the 3 rd interspace (3L) and inner part of it (over the sternum). One case complicated by PS gave no conclusive data as to the PMI, because of the superposition of the respective systolic murmurs. 


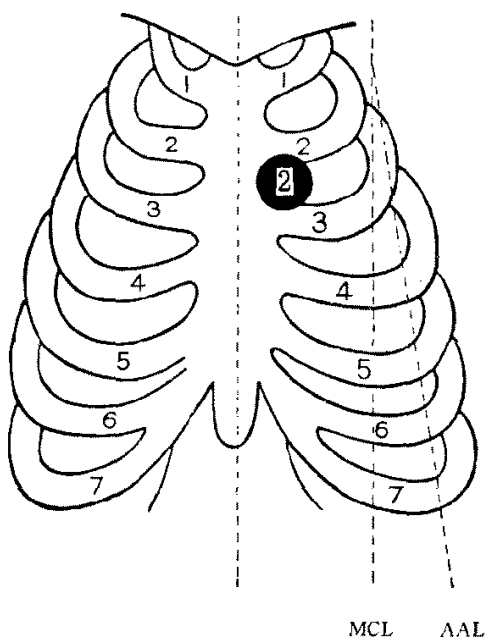

Supracristal VSD

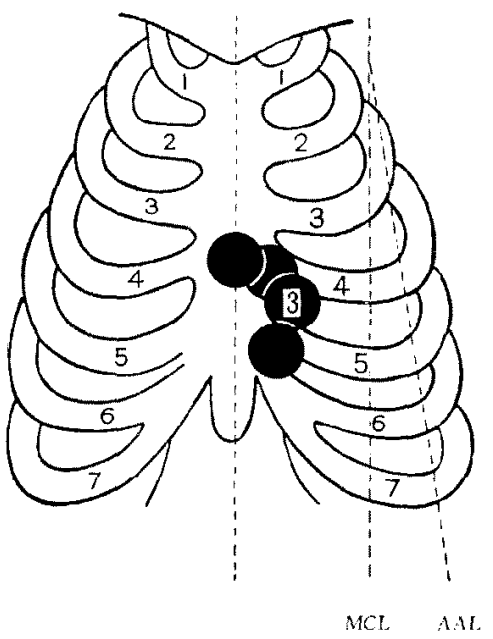

Inflow Tract VSD

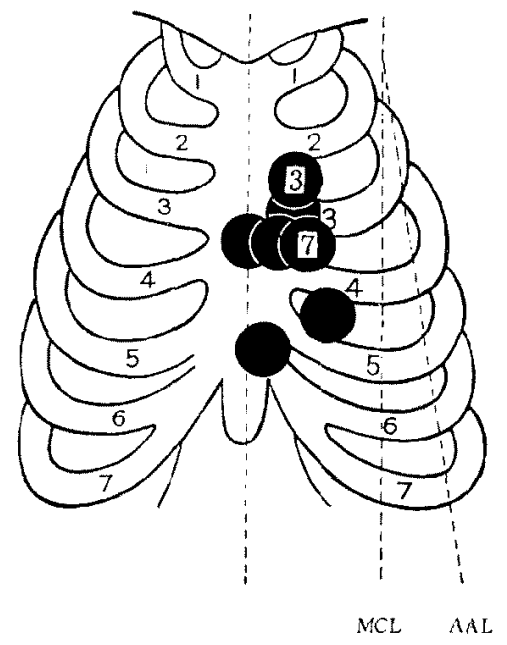

Outflow Tract VSD

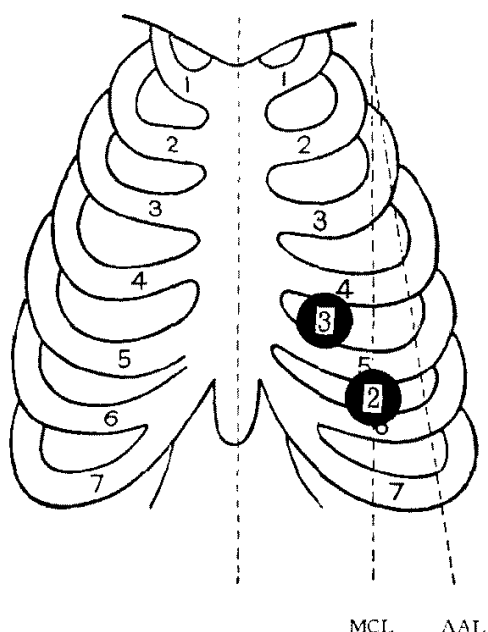

Muscular VSD

Fig. 6. Distribution of PMI in various forms of VSD. The anatomical type of defect was summed up in all cases and the corresponding PMI was schematically shown by black circle. One circle indicates single case. The figures in the circle indicates the number of the corresponding cases encountered. As stated in the text, it is reasonable to anticipate the site of defect by the location of precordial PMI, if the constitution of body and size and shape of the heart are taken into consideration. $\mathrm{MCL}=$ mid-clavicular line, $\mathrm{AAL}=$ anterior axillary line. Muscular VSD in this figure means the apical muscular type of defect. 
3) Inflow tract VSD (6 cases): The defect is in the muscular portion of the inflow tract below the septal leaflet of the tricuspid valve. The murmur was at the tricuspid area, but the PMI was present at the site where the RV pressure tracing was depicted (Fig. 8). The artificial tricuspid insufficiency should be ruled out by the careful monitoring (intracardiac auscultation). Furthermore, left ventricular-right atrial shunt must be excluded by the facts that there was no or very soft murmur in the RA when the catheter was pushed from RA to RV and that the PMI was in the RV and not in the RA while the pull-



Fig. 7. Patient H. A., 19-year-old male. Outflow tract VSD. The precordial PMI was in 3L and the intensity was V/VI. Though the murmur was transmitted toward PA, the intracardiac PMI was in the outflow tract and both intracardiac and precordial PMIs had definite topographic relationship. Though it was difficult to hold the catheter tip at the PMI (pressure curve was deformed and soon later the catheter jumped out from the PMI), the oxygen content measured at this site was significantly high (cf. Table I). The pullback tracing showed sudden decrease in intensity of the murmur toward the inflow tract. Filter characteristics: H1. 


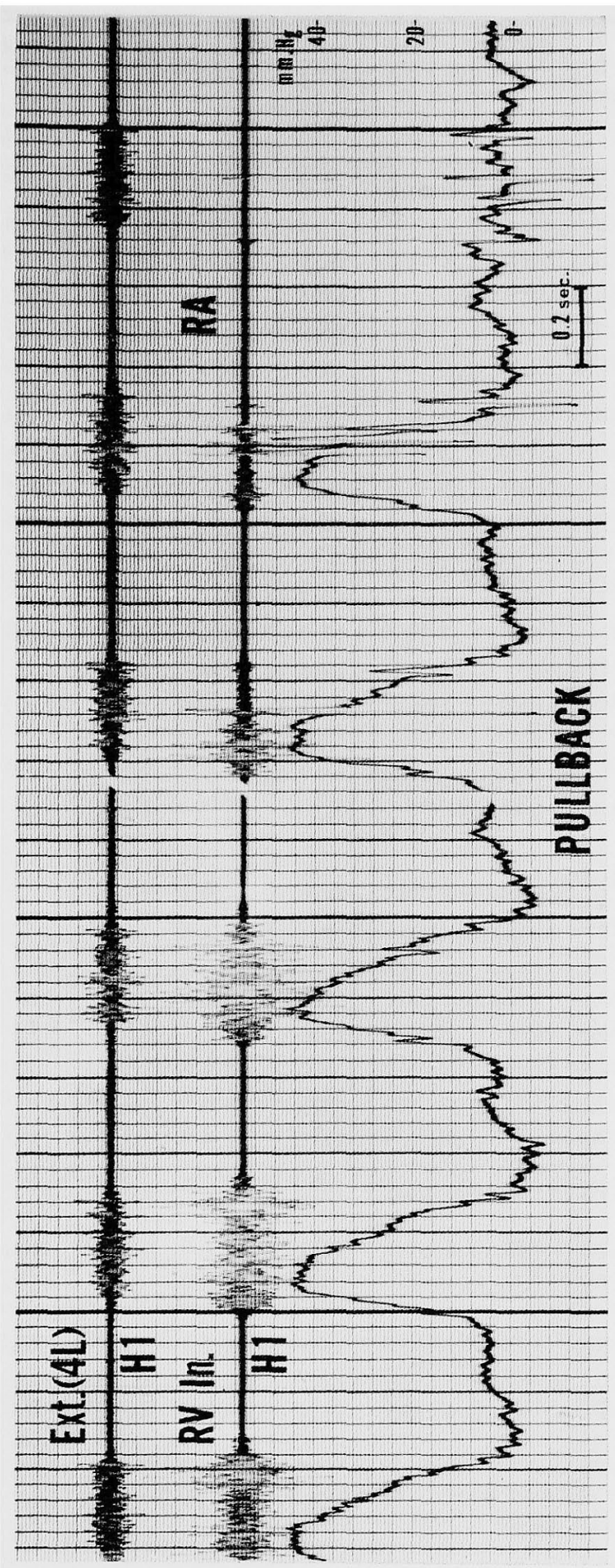


Table I. Hemodynamic

\begin{tabular}{|c|c|c|c|c|c|c|c|c|c|}
\hline \multirow{3}{*}{ Case } & \multirow{3}{*}{ Age } & \multirow{3}{*}{ Sex } & \multirow{3}{*}{ Diagnosis } & \multirow{3}{*}{$\begin{array}{l}\text { PMI of VSD } \\
\text { Murmur in } \\
\text { RV }\end{array}$} & \multirow{3}{*}{ SVC } & \multirow{3}{*}{ IVC } & & \multicolumn{2}{|c|}{ Oxygen Conten } \\
\hline & & & & & & & & \multicolumn{2}{|c|}{$\mathrm{RV}$} \\
\hline & & & & & & & & Inflow & Mid. \\
\hline H.A. & 19 & $\mathbf{M}$ & VSD & Outflow tract & 14.6 & 15.3 & 15.6 & & 15.6 \\
\hline M.O. & 20 & F & VSD & , & 11.8 & 12.0 & 12.1 & 11.5 & 12.6 \\
\hline H.I. & 26 & $\mathbf{M}$ & VSD & " & 16.3 & 15.8 & 16.8 & & \\
\hline S.Y. & 29 & $\mathbf{M}$ & VSD & $"$ & 11.7 & 12.8 & 12.3 & 12.6 & \\
\hline M.Y. & 12 & $\mathbf{F}$ & VSD & $"$ & 12.3 & 12.3 & 11.9 & 12.2 & \\
\hline K.U. & 19 & $\mathbf{F}$ & VSD & $"$ & 8.8 & 9.3 & 9.5 & 9.5 & \\
\hline M.K. & 16 & $\mathbf{M}$ & VSD & Intlow tract & 11.8 & 12.8 & 12.3 & 15.8 & \\
\hline T.M. & 22 & $\mathbf{M}$ & VSD & " & 12.7 & 13.7 & 13.3 & 16.3 & 13.2 \\
\hline S.K. & 25 & $\mathbf{M}$ & VSD & , & 11.7 & 12.8 & 12.9 & 16.1 & \\
\hline A.K. & 18 & $F$ & VSD & $"$ & 11.4 & 11.3 & 11.5 & 12.9 & 11.8 \\
\hline S.T. & 16 & $\mathbf{M}$ & VSD & $\begin{array}{l}\text { Apical } \\
\text { muscular }\end{array}$ & 14.3 & 14.6 & 15.5 & 16.1 & \\
\hline K.O. & 24 & $\mathbf{M}$ & VSD & $"$ & 11.0 & 10.8 & 11.1 & 12.3 & 12.5 \\
\hline T.N. & 29 & $\mathbf{M}$ & VSD & , & 12.3 & 12.4 & 12.6 & & 12.2 \\
\hline C.M. & 22 & $\mathbf{F}$ & VSD & $"$ & 11.4 & 11.5 & 11.6 & 11.5 & 11.3 \\
\hline H.T. & 20 & F & VSD & $\begin{array}{l}\text { Outflow } \\
+ \text { Inflow tract }\end{array}$ & 12.5 & 12.2 & 11.9 & 11.9 & \\
\hline K.T. & 16 & F & VSD & $\begin{array}{l}\text { Supracristal } \\
+ \text { Inflow tract }\end{array}$ & - & - & - & - & - \\
\hline S.Y. & 33 & $\mathbf{M}$ & $\begin{array}{l}\text { VSD, Pulm. } \\
\text { hypertension }\end{array}$ & Outflow tract & 12.6 & 11.8 & 13.4 & & 17.4 \\
\hline G.O. & 34 & $\mathbf{M}$ & $\begin{array}{l}\text { VSD, Pulm. } \\
\text { hypertension }\end{array}$ & No murmur & 12.4 & 14.6 & 14.6 & & \\
\hline M.N. & 24 & $\mathbf{M}$ & $\mathrm{VSD}+\mathrm{AI}$ & Outflow tract & 12.5 & 13.0 & 13.0 & 12.3 & \\
\hline S.A. & 16 & $\mathbf{M}$ & $\mathrm{VSD}+\mathrm{AI}$ & $"$ & 10.6 & 11.6 & 11.4 & 11.9 & 11.7 \\
\hline F.U. & 16 & F & $\mathrm{VSD}+\mathrm{AI}$ & $"$ & 9.0 & 9.5 & 9.4 & 10.0 & \\
\hline E.G. & 20 & $F$ & $\mathrm{VSD}+\mathrm{AI}$ & $"$ & 8.9 & 9.0 & 9.6 & & 10.7 \\
\hline K.K. & 18 & $\mathrm{M}$ & $\mathrm{VSD}+\mathrm{AI}$ & $"$ & 11.9 & 11.4 & 12.0 & 13.2 & 14.3 \\
\hline K.I. & 18 & $\mathrm{M}$ & $\mathrm{VSD}+\mathrm{PS}$ & Outflow tract & 12.0 & 13.1 & 12.9 & & \\
\hline H.O. & 31 & $\mathbf{M}$ & $\mathrm{VSD}+\mathrm{PS}$ & Outflow tract & 12.7 & 13.2 & 13.1 & 12.6 & \\
\hline F.T. & 23 & $\mathrm{~F}$ & $\mathrm{VSD}+\mathrm{PS}$ & Supracristal & 10.3 & 12.2 & 11.4 & 11.0 & \\
\hline K.Y. & 16 & $\mathbf{M}$ & $\mathrm{VSD}+\mathrm{MI}$ & $\begin{array}{l}\text { Apical } \\
\text { muscular }\end{array}$ & 14.7 & 15.5 & 15.3 & 15.6 & \\
\hline H.S. & 19 & $\mathrm{~F}$ & $\mathrm{VSD}+\mathrm{PDA}$ & Outflow tract & 11.4 & & 10.6 & 10.8 & 12.8 \\
\hline
\end{tabular}

$* \mathrm{~L} \rightarrow \mathrm{R}$ Shunt $(\%)=\mathrm{L} \rightarrow \mathrm{R}$ Shunt $(\mathrm{L} . / \mathrm{min}$.$) / Pulmonary Flow (\mathrm{L} . / \mathrm{min}) \times$.

** Measured during the phase of blood pressure elevation by methoxamine.

(Bold figures are the samples at the site of PMI of VSD murmur). 
Data

\begin{tabular}{|c|c|c|c|c|c|c|c|c|c|c|}
\hline \multicolumn{4}{|c|}{ (Vol. \%) } & \multicolumn{4}{|c|}{ Pressure (mm.Hg) } & \multirow{3}{*}{$\begin{array}{c}\text { Pulmo- } \\
\text { nary } \\
\text { Flow } \\
\text { (L./min.) }\end{array}$} & \multirow{3}{*}{$\begin{array}{c}\mathrm{L} \rightarrow \mathrm{R}^{*} \\
\text { Shunt } \\
(\%)\end{array}$} & \multirow{3}{*}{$\begin{array}{l}\text { Systemic } \\
\text { Cardiac } \\
\text { Index } \\
(\mathrm{L} . / \mathrm{min} . / \\
\left.\mathrm{M} .^{2}\right)\end{array}$} \\
\hline \multicolumn{2}{|c|}{ RV } & \multirow{2}{*}{ PA } & \multirow{2}{*}{$\begin{array}{l}\text { Sys- } \\
\text { temic }\end{array}$} & \multicolumn{2}{|c|}{ RV } & \multirow{2}{*}{ PA } & \multirow{2}{*}{$\begin{array}{l}\text { Sys- } \\
\text { temic }\end{array}$} & & & \\
\hline Apex & Outflow & & & Inflow & Outfiow & & & & & \\
\hline & 17.1 & 16.2 & 18.5 & $35 / 1-5$ & $23 / 3-7$ & $23 / 12$ & $115 / 70$ & 9.3 & 30 & 4.0 \\
\hline & 12.6 & 12.5 & 15.8 & $19 / 2-5$ & $15 / 1-2$ & $14 / 4$ & $150 / 85$ & 6.3 & 16 & 3.4 \\
\hline & 16.6 & 16.7 & 18.8 & & $30 / 0-3$ & $24 / 10$ & $108 / 61$ & 9.1 & 15 & 6.2 \\
\hline & & 13.2 & 15.2 & $28 / 3-8$ & & $25 / 12$ & $128 / 50$ & 7.5 & 31 & 3.1 \\
\hline & 12.2 & 12.1 & 15.1 & $26 / 2-7$ & $23 / 3-7$ & $21 / 11$ & $112 / 63$ & 7.5 & - & 5.3 \\
\hline & 10.0 & 10.4 & 13.0 & $24 / 0-6$ & $22 / 0-6$ & $20 / 8$ & $108 / 66$ & 8.8 & 26 & 3.8 \\
\hline \multirow[t]{4}{*}{12.8} & 12.5 & 13.2 & 16.7 & $24 / 3-5$ & $17 / 2-4$ & $15 / 8$ & $138 / 66$ & 7.8 & 20 & 3.5 \\
\hline & & 14.7 & 17.7 & $25 / 0-5$ & $23 / 0-4$ & $20 / 7$ & $120 / 70$ & 12.0 & 50 & 3.6 \\
\hline & 13.7 & 13.7 & 16.1 & $29 / 3-8$ & $26 / 5-8$ & $20 / 10$ & $100 / 60$ & 5.3 & 31 & 2.4 \\
\hline & 11.9 & 12.5 & 15.7 & $20 / 0-5$ & $20 / 0-4$ & $19 / 8$ & $112 / 70$ & 3.9 & 32 & 2.0 \\
\hline \multirow[t]{4}{*}{17.3} & 16.0 & 15.7 & 18.5 & $34 / 2-9$ & $31 / 2-9$ & $25 / 11$ & $120 / 66$ & 8.8 & 30 & 4.0 \\
\hline & 12.6 & 12.1 & 15.8 & $25 / 0-2$ & $25 / 0-2$ & $20 / 4$ & $106 / 62$ & 4.8 & 29 & 2.3 \\
\hline & & 12.7 & 16.6 & $24 / 2-5$ & $20 / 0-4$ & $18 / 8$ & $114 / 74$ & 2.7 & - & 1.7 \\
\hline & 11.8 & 11.5 & 14.5 & $20 / 0-5$ & $20 / 0-6$ & $22 / 12$ & $130 / 77$ & 7.2 & 一 & 4.4 \\
\hline 11.5 & 13.5 & 13.6 & 15.9 & $40 / 0-5$ & $30 / 0-5$ & $30 / 11$ & $97 / 59$ & 10.3 & 48 & 3.7 \\
\hline \multirow[t]{8}{*}{-} & - & - & - & - & - & $20 / 5$ & $118 / 50$ & - & - & - \\
\hline & 16.9 & 16.7 & 17.5 & & $70 / 0-8$ & $74 / 32$ & $110 / 73$ & 27.8 & 85 & 3.1 \\
\hline & 16.7 & 16.7 & 19.0 & $90 / 0-4$ & $90 / 0-4$ & $100 / 48$ & $116 / 52$ & 4.1 & 40 & 2.6 \\
\hline & 14.2 & 13.8 & 17.3 & $33 / 0-5$ & $30 / 0-5$ & $34 / 17$ & $160 / 40$ & 5.6 & 20 & 3.2 \\
\hline & 12.8 & 13.6 & 15.6 & $55 / 0-8$ & $42 / 0-5$ & $40 / 10$ & $158 / 68$ & 10.7 & 50 & 3.9 \\
\hline & 11.4 & 11.6 & 13.0 & & $48 / 0-5$ & $52 / 20$ & $100 / 30$ & 10.2 & 54 & 3.8 \\
\hline & 10.7 & 10.2 & 13.4 & $24 /-3-5$ & $24 / 0-5$ & $24 / 11$ & $160 / 46$ & 6.8 & 33 & 3.1 \\
\hline & 13.9 & 13.2 & 16.0 & $47 / 2-8$ & $25 / 2-10$ & $22 / 14$ & $132 / 44$ & 9.1 & 35 & 3.5 \\
\hline \multirow[t]{3}{*}{13.1} & $\begin{array}{l}14.3 \\
15.5^{* * *}\end{array}$ & 14.1 & 15.5 & $34 / 4-8$ & & $18 / 10$ & $130 / 70$ & 19.9 & 56 & 4.6 \\
\hline & 12.9 & 14.1 & 18.2 & $152 / 1-20$ & $24 / 10$ & $24 / 8$ & $148 / 83$ & 9.6 & 20 & 5.4 \\
\hline & 12.0 & 12.6 & 15.1 & $65 / 0-5$ & $23 / 0-5$ & $17 / 5$ & $112 / 60$ & 8.0 & 26 & 4.3 \\
\hline \multirow[t]{2}{*}{15.9} & 15.5 & 15.4 & 18.9 & $15 / 0-2$ & $15 / 0-2$ & $15 / 4$ & $108 / 60$ & 7.2 & - & 4.7 \\
\hline & 15.2 & 12.9 & 16.4 & $43 / 3-11$ & $34 / 3-8$ & $34 / 17$ & $132 / 60$ & 8.3 & 58 & 2.1 \\
\hline
\end{tabular}


back tracing was recorded. The site of the intracardiac PMI was lower than that of the outflow tract VSD and the precordial projection was mainly in the 4 th interspace (4L) and median to it (Fig. $6:$ lower left).

4) Apical muscular VSD (5 cases): These 5 cases had the communication near the right ventricular apex. In this instance, the catheter microphone may not come across the intracardiac PMI by the pullback maneuver, therefore the PMI may be missed by routine method. The precordial PMI was usually outside the usual pathway of the catheter, so that the catheter must be pushed toward the apex to search for the intracardiac PMI which was fairly localized. The precordial PMI was between the apex and the lower left sternal border (Fig. 6 : lower right), and no case had its PMI along the sternal margin.

\section{Problem of the Blood Sampling:}

As the intracardiac PMI of the murmur of VSD is the site of interventricular communication, the blood sampling was attempted at this point and the analyzed data were compared with those of randam sampling (Table I). Seven cases were selected to this special approach, and the careful intracardiac auscultation was performed during the teleological sampling in order to secure the site of PMI. As shown by the bold figures in Table I, the aimed samples showed higher oxygen content of 1 to $3 \mathrm{vol} \%$ in each case. Following the administration of methoxamine, the figure approached to the level of the arterial sample. The same was true to the samples obtained from the site immediately beneath the precordial PMI.

\section{Discussion}

\section{Clinical significance of I-PCG in the diagnosis of VSD :}

Though some authors ${ }^{17,25)-28}$ described a few exceptions, the ability to indicate the origin of a given murmur has been regarded as the most important diagnostic significance of I-PGG. ${ }^{1-5}{ }^{-5}$ According to Lewis et al. ${ }^{11}$ the regurgitant murmur of VSD was localized to the area of the defect and may be present in the whole cavity of the RV whenever the murmur was intense. They presented a case combined with pulmonic stenosis, in which the selective increase of oxygen content was observed in the outflow tract along with the intensification of the murmur. Feruglio and Gunton ${ }^{15}$ stated that the characteristic pansystolic murmur within the RV was usually loudest in the outflow tract and attenuated toward the apex with an exception of traumatic VSD. Generally speaking, some degree of transmission of the murmur toward PA was noticed, but it was barely transmitted to $\mathrm{R} \Lambda$. These data, as confirmed by the previous 
authors, ${ }^{51-9), 11(-14), 16 /-19)}$ are consistent with the results of the present study. Particularly, the value of I-PCG for the detection of small VSD or so-called "no-shunt" VSD (the shunt is so small that the result of oxygen study is equivocal) is extremely important. ${ }^{16)-19), 29)}$ Recently, Wennevold ${ }^{19)}$ described 13 cases with very small left-to-right shunt, in which I-PCG was diagnostic and the oxygen study failed to demonstrate the shunt. Sears et al. ${ }^{17}$ ) also documented 4 such cases, and Tourniaire ${ }^{18)}$ described 6 cases. Leatham and Segal, ${ }^{16)}$ discussing the value of I-PCG, emphasized the high sensitivity of indicator dilution techniques to detect the small shunt, but the exact localization of septal defect in the RV was not justifiable by these methods in most cases of VSD.11) I-PCG is, in fact, expected to detect the regurgitant jet, so that is able to locate the defect. Blood sampling performed at the site of defect further confirms the left-to-right shunt, contributing to the confirmation of the diagnosis. This was proposed by some authors and the present results confirmed the fact. In this respect, the administration of vasopressor agent, such as phenylephrine ${ }^{30)}$ or methoxamine ${ }^{22)}$ seems to be useful to make the diagnosis conclusive, not only by making the murmur typical, but also detecting the increased oxygenation at the site of defect. Furthermore, the topographically close relationship between the intracardiac and precordial PMIs of the murmur of VSD, as proved by the present study, facilitates to detect the highly oxygenated sample immediately beneath the precordial PMI. This is of great utility, and the practical value of precordial PMI for the sampling without I-PCG has been proved by the subsequent material in our laboratory.

\section{Physiological significance of PMI of VSD:}

As the previous papers and the present study confirmed, the greatest intensity of the regurgitant systolic murmur of VSD is observed at the site of defect and the slight movement of the catheter $(1$ to $2 \mathrm{~cm}$. from the PMI) causes the significant decrease in the intensity. From the physiological standpoint, it seems important that there is a close topographic relationship between the 2 PMIs (intracardiac and precordial) and, therefore, the anatomical variety of the site of defect is manifested by the wide spread of the precordial PMI, permitting to anticipate the location of defect based on the precordial PMI*.

Studying the behavior of the spread of cardiovascular sounds over the precordium, Faber and Burton ${ }^{31 \text {, 32) }}$ concluded that the so-called " auscultatory areas" are the "secondary sources", from where the cardiovascular sound originating from the heart and great vessels spreads over the chest wall. These

* Considering the variety of cardiac size and shape, the apex beat or more accurately the skiagram of chest is preferably utilized for the final ciecision. 
areas, according to the authors, are the places where the chest wall anatomically contacts directly with the cardiovascular structures. Assuming that their view is right, the precordial PMI which coincides with the center of the secondary source must be located exclusively at the center of the mid-precordium (i.e. $3 \mathrm{~L}$ to $4 \mathrm{~L}$ ) in case of VSD irrespective of the anatomical variety of the defect, because $3 \mathrm{~L}$ or $4 \mathrm{~L}$ is the point of contact of the $\mathrm{RV}$ with the chest wall in cases of maladie de Roger. However, the present study disclosed that there was a wide distribution of both intracardiac and precordial PMIs and that the precordial PMI was located exactly in the area where the intracardiac PMI was projected to the chest wall in a dorsoventral direction. These facts seem to suggest that, in addition to the way of transmission proposed by Faber and Burton, there is another route of sound propagation, i.e., the direct transmission from the heart to the chest wall via the shortest route. Though this concept was denied by Faber and Burton, Ogawa et al. ${ }^{33)}$ demonstrated the intensity distribution of the systolic murmur of VSD and suggested the presence of several pathways of transmission of cardiovascular sound from its origin and the existence of the direct transmission in a certain range of intensity or frequency of the murmur. To explain a wide distribution of the PMI of VSD, Ogawa ${ }^{34)}$ postulated the broad contact of the RV and the chest wall. However, it is not the case in all cases with small shunt, so that the present authors still have an opinion that the cardiovascular sound has its precordial PMI at the nearest point to the origin. According to Castle, ${ }^{35)}$ the regurgitant jet of VSD is directed anteriorly and slightly rightward, so that the commonest form of VSD (outflow tract VSD) has the precordial PMI in 3L, to where the direction of jet is faced. In other words, the nearest precordial area in this instance is in $3 \mathrm{~L}$ (or $4 \mathrm{~L}$ ) and the murmur travels to this area by the shortest route (direct transmission). Similarly, the precordial PMI of supracristal VSD is in the nearest point to the origin (i.e., 2L) and the one of apical muscular VSD is near the apex or the mid-portion between apex and LLSB. These precordial PMIs are quite far from each other, not because of the wide contact of RV with the thoracic wall, but because each PMI is determined by the intracardiac PMI which is in any places even within the RV. The work from our laboratory disclosed the same relationship in various cardiac murmurs originating from the right-sided heart, ${ }^{36)}$ but the relationship in cases of VSD was the most conspicuous*.

Recently, Luisada and his collaborators ${ }^{38)-411}$ schematically depicated the precordial map of various cardiovascular sounds based on the clinical cxperience

* For most of the murmurs originating from the left-sided heart, the same principle is still valid. However, some degree of solid angle should be taken into consideration for the murmurs originating deeply in the chest cavity, such as the murmur of mitral or aortic regurgitation (particularly of rightsided aortic diastolic murmur $\left.{ }^{37}\right)$. 
and the knowledge supplied by physiological studies including intracardiac phonocardiography, and revised the classical "ausculatory areas". Basically, the regurgitant systolic murmur of VSD situates in the "right ventricular area ${ }^{38)}$ ", and the present study confirmed their veiw. However, the actual site of PMI is in the shaded area occupied by both right and left ventricles in the figure of "normal heart" or at the boundary between both ventricles in the figure of "left ventricular enlargement". Therefore, in a strict scnse, the view that regards the murmur of VSD as a sort of right-sided murmurs (such as tricuspid murmurs in the presence of enlarged RV) may be misleading. Similarly, the 2nd left interspace (2L) may be a part of the right ventricular area in cases of supracristal VSD, as Reynolds ${ }^{42}$ ) stressed the diagnostic significance of the thrill and murmur in 2L. Most adequately, the name of "inter ventricular septal area " will be reserved for the group of precordial PMI of VSD. This seems to be important clinically, because the topographic correspondence of the 2 PMIs quite often enables us to make the precise anatomical diagnosis of VSD.

Addendum: Since this paper was submitted for publication, Rautenburg and Menner4) reported 84 phonocatheter studies of various types of septal defect. They proved the presence of VSD in 21 out of 68 cases by I-PGG alone, and emphasized the diagnostic accuracy of this technique to detect the small shunt.

\section{ACKNOWLEDGMENT}

The authors are greatly indebted to Drs. H. Yasuda, Y. Takabatake, K. Ueda, H. Matsuo, H. Nakamura, K. Inoue, Y. Uchida, K. Ozeki, and Y. Sasaki for their collaboration with us.

\section{REFERENCES}

1. Lewis, D. H., Ertugrul, A., Deitz, G. W., Wallace, J. D., Brown, J. R., Jr., and Moghadam, A.-N. : Pediatrics 23: 837, 1959.

2. Feruglio, G. A.: Am. Heart J. 58 : 827, 1959.

3. Yamakawa, K.: Jap. Circulat. J. 24: 932, 1960.

4. Effert, S., Grosse-Brockhoff, F., and Loogen, F.: Dtsch. med. Wschr. 85 : 2316, 1960.

5. Ssulić, P., Baculard, P., Bouchard, F., Cornu, C., Laurens, P., and Wolff, I. : Arch. mal. coeur 54 : Suppl. I: 1, 1961.

6. Yarza Iriarte, J. M., Iriarte Ezcurdia, M., Rodriquez, R., De Azua, C., Calderon Sancez, A., and Laso-Nunez, J. L. : Rev. Españ. Cardiol. 14 : 194, 1961.

7. Luisada, A. A., Liu, C. K., Szatkowski, J., and Slodki, S. J. : Acta cardiol. 18: 533, 1963.

8. Feruglio, G. A.: Intracardiac Auscultation and Phonocardiography (techniques and clinical applications). Edizioni Minerva Medica, Torino, p. 64, 1964.

9. Segal, B. L., Novack, P., and Kasparian, H. : Am. J. Cardiol, 13 : 188, 1964. 
10. Leonard, J.J. and Kroetz, F. W. : Mod. Concepts Cardiovasc. Dis. 35 : 69, 1966.

11. Rautenburg, H. W.: Med. Welt 17:690, 1966.

12. Dahl, M. : Acta Paediat. Scand. Suppl. $169: 1,1966$.

13. Wennevold, A.: Danish Med. Bull. $13: 162,1966$.

14. Wooley, C. F., Levin, H. S., Leighton, R. F., Goodwin, R. S., and Ryan, J. M. : Am. J. Med. 42: $248,1967$.

15. Feruglio, G. A. and Gunton, R. W. : Girculation $21: 49,1960$.

16. Leatham, A. and Segal, B.: Circulation 25: 318, 1962.

17. Sears, G. A., Movafach, P., and Manning, G. W. : Am. J. Med. Sci. 243 : 775, 1962.

18. Tourniaire, A., Deyrieux, F., Tartulier, M., and Blum, J. : Arch. mal. coeur 57 : 919, 1964.

19. Wennevold, A.: Acta med. Scand. 179: 285, 1966.

20. Sakamoto, T., Uozumi, Z. Kaito, G., and Ueda, H. : Jap. Heart J. 7 : 154, 1966.

21. Ueda, H., Sakamoto, T., Uozumi, Z., Kobayashi, T., Kawai, N., Yamada, T., Inoue, K., Ichinose, S., Watanabe, H., and Kaito, G. : Naika 15: 951 and 1155, 1965 (in Japanese).

22. Ueda, H., Sakamoto, T., Uozumi, Z., Inoue, K., Kawai, N., and Yamada, T. : Jap. Heart J. $7: 204,1966$.

23. Schloss, F. and Strasberg, M. : J. Acoust. Soc. America 34 : 958, 1962.

24. Leatham, A.: Lancet $\mathbf{i}: 463,1958$.

25. Heintzen, P. and Vietor, K. W.: Z. Kreislaufforschg. 51 : 932, 1962.

26. Perry, L. W., Wells, C. R. E., and Voci, G. : Am. Heart J. 68 : 443, 1964.

27. Reploh, H. D., Hilgenberg, E., and Bender, F.: Z. Kreislaufforschg. 54 : 473, 1965.

28. Wennevold, A. : Acta med. Scand. 179 : 595, 1966.

29. Van der Hauwaert, L. and Nadas, A. S. : Circulation $23: 886,1961$.

30. Schrire, V., Vogelpoel, L., Beck, W., Nellen, M., and Swancpoel, A. : Am. Heart J. 62 : 225, 1961.

31. Faber, J. J. and Burton, A. C. : Circulat. Res. 11: 96, 1962.

32. Faber, J. J. and Burton, A. C. : Canad, Med. Ass. J. 91 : 120, 1964.

33. Ogawa, T., Takada, H., Yoshida, S., Hisada, S., Horikoshi, K., Hotta, S., Nagaya, T., Mizuno, Y., and Hibino, S.: Jap. Heart J. $7: 448,1966$.

34. Ogawa, T.: Jap. Circulat. J. 32:211, 1968 (in Japanese).

35. Castle, R. F.: J. A. M. A. $199: 838,1967$.

36. Ueda, H., Yasuda, H., Sakamoto, T., Takabatake, Y., Uozumi, Z., Kuroiwa, A., Ueda, K., Kawai, N., Yamada, T., Matsuo, H., Nakamura, H., Inoue, K., Chang, S. Y., Uchida, Y., Ozeki, K., and Sasaki, Y.: Presented at the 32nd Annual Meeting of the Jap. Circulation Soc., Kurume, March, 1968.

37. Sakamoto, T., Kawai, N., Uozumi, Z., Yamada, T., Inoue, K., Chang, S. Y., and Ueda, H. : Jap. Heart J. $9: 117,1968$.

38. Shah, P. M., Slodki, S. J., and Luisada, A. A. : Am. J. Med. 36 : 293, 1964 ; Mal. Cardíovasc. 5 : 37, 1964; Acta cardiol. 19; 111, 1964.

39. Luisada, A. A. and Shah, P. M. : A.m. J. Cardiol. $11: 774,1963$.

40. Sainani, G. S. and Luisada, A. A. : Am. J. Cardiol. 19: 788, 1967.

41. Sainani, G. S., Luisada, A. A., and Gupta, P. : Acta cardiol. 23 : 152, 1968.

42. Reynolds, J. L.: Am. J. Cardiol. $18: 610,1966$.

43. Sakamoto, T.: Respiration \& Circulation 14: 673, 1966 (in Japanese).

44. Rautenburg, H. W. and Menner, K.: Cardiologia 51 : 359, 1967. 